\title{
Ranking very young Pinus radiata families for acoustic stiffness and validation by microfibril angle
}

\author{
Monika Sharma $^{1}$ - Luis A. Apiolaza ${ }^{1} \cdot$ Shakti Chauhan $^{2}$ - J. Paul Mclean ${ }^{3}$. \\ Jan Wikaira ${ }^{1}$
}

Received: 6 July 2014 / Accepted: 27 October 2015 / Published online: 16 November 2015

(C) INRA and Springer-Verlag France 2015. This article is published with open access at Springerlink.com

\begin{abstract}
- Key message Acoustic techniques can be utilised to rank a large population of young trees for stiffness and stability for breeding purposes.

- Introduction This study sought to validate new approaches to rapid, very early screening and selection of radiata pine families, using microfibril angle (MFA) as a reference for comparative purposes.

- Method A key feature was tilting the trees at an angle of $\sim 30^{\circ}$ after the initial 12 months of growth in order to force production of opposite wood (OW) and compression wood $(\mathrm{CW})$ and prevent the co-mingling of the two distinctive wood
\end{abstract}

Handling Editor: Erwin Dreyer

Contribution of the co-authors Luis A. Apiolaza supervised the work and helped in analysing the data. Shakti Chauhan designed the experiment and helped in sample preparation and measuring physical properties. J. Paul Mclean and Jan Wikaira helped with X-ray diffraction measurements and calculating MFA from X-ray diffraction images.

Monika Sharma

monika.sharma@canterbury.ac.nz

Luis A. Apiolaza

luis.apiolaza@canterbury.ac.nz

Shakti Chauhan

shakti32@gmail.com

J. Paul Mclean

paul.mclean@forestry.gsi.gov.uk

Jan Wikaira

jan.wikaira@canterbury.ac.nz

1 School of Forestry, University of Canterbury, Private Bag 4800, Christchurch 8140, New Zealand

2 Malleswaram, Institute of Wood and Science, Bangalore 560003, India

3 Nothern Research Station Roslin, Forest Research, Midlothian EH25 9SY, UK types as occurs 'at random' within vertical stems. After 34 months, OW and $\mathrm{CW}$ materials were characterised independently for acoustic velocity $(V)$, dynamic modulus of elasticity $\left(\mathrm{MOE}_{\text {dynamic }}\right)$, basic density and longitudinal shrinkage. Finally, MFA were determined with X-ray diffraction.

- Result No phenotypic correlation was observed between OW and CW wood properties. The Spearman ranking correlation between $V^{2}$ and MFA values in OW was 0.81 .

- Conclusion We show that families or individual trees with superior wood properties can be screened at this young age using acoustics. Further, the same outcomes can be achieved as with X-ray diffraction (MFA) but more cheaply and rapidly.

Keywords Radiata pine $\cdot$ Tree breeding $\cdot$ MFA $\cdot$ Acoustic velocity $\cdot$ Dimensional stability

\section{Introduction}

Low stiffness and instability (or propensity to warp) are key problems in the industrial utilisation of softwoods for structural and appearance timber. These detrimental properties are very evident in the corewood of radiata pine (Pinus radiata $\mathrm{D}$. Don), i.e., wood formed in the first 10 rings from the pith (Burdon et al. 2004). In fast-grown radiata pine, this 10-ring corewood zone constitutes around $50 \%$ of the merchantable timber in a 25-year-old tree (Cown et al. 1991). For this reason, Walker and Butterfield (1996) proposed that improving corewood properties should be a priority. Further, the current price differential between a box-grade material (the worst of the corewood) and utilitarian grades for framing (MGP10) is much greater than that between utilitarian grades and premium grades for engineering (MGP12) and finishing purposes (Apiolaza et al. 2013). Considering the current value of timber (Drew and Downes 2010) graded according to the current 
Australia/New Zealand standards (AS/NZS 1748), box grade (i.e., ungraded, lower quality timber) is discounted A $\$ 250 / \mathrm{m}^{3}$ (56\%) relative to MGP10, while the premium for moving from MGP10 to MGP12 is only $\mathrm{A} \$ 60 / \mathrm{m}^{3}$ (12\%). In order to focus on corewood properties, it is possible to collect temporal measurements of those properties on older trees, or we can work directly with young trees ( $<3$ years), as we know the worst wood is at the centre of the tree and gradually improves with ring number (Xu and Walker 2004). Additionally, shorter breeding cycles should outweigh any lower accuracy in early selection (Apiolaza 2009).

A problem with characterising wood in very young radiata pine stems is that young trees are rarely perfectly straight and stem wander results in a 'seemingly random' distribution of compression wood (CW) that is not under experimental control within a cross section. The distribution of $\mathrm{CW}$ is not strictly random as $\mathrm{CW}$ is a phenotypic response of conifers to environmental stresses, whereby it serves to reorient the stem toward the vertical (Timell 1986). In order to perform this function, CW in radiata pine has different physical, mechanical (Chauhan et al. 2013) and chemical compositions (Brennan et al. 2012) to opposite wood (OW) in the same trees. Burdon (1975) examined a 12-year-old radiata pine growing on four different sites in New Zealand and estimated that 30 to $45 \%$ of the stem volume contained mild to severe $\mathrm{CW}$. This intermixing of $\mathrm{CW}$ with $\mathrm{OW}$ introduces uncertainties into the analysis that makes the prediction of 'true' normal wood properties problematic, unless the two wood types are segregated. Chauhan et al. (2013) provided a solution by tilting the young trees during growth and characterising $\mathrm{OW}$ and $\mathrm{CW}$ properties separately. In this study, as in Chauhan et al. (2013), trees were tilted during growth to produce $\mathrm{OW}$ free from $\mathrm{CW}$, so as to be representative of normal wood, and to demonstrate how the technique can be used for superior genetic selection with respect to better corewood properties.

The angle that the cellulose microfibrils in the dominant S2 layer of the secondary wall deviates from the longitudinal axis of the cell is known as the microfibril angle (MFA). MFA has an important influence on stiffness and dimensional stability of corewood timber. Cave (1969) measured the change in cell wall stiffness of radiata pine as a function of MFA and observed a fourfold increase in stiffness from pith to cambium as the MFA decreased from $40^{\circ}$ to $10^{\circ}$. High MFA also results in high longitudinal shrinkage (Meylan 1968), and such wood is liable to warp on drying. The significant variation in MFA in radiata pine and its degree of genetic control (Lindström et al. 2004; Dungey et al. 2006) mean that stiffness can be improved by selecting young trees with low MFA. A secondary factor influencing wood properties is the amount of solid wood present per unit volume, as axial stiffness increases linearly with density (Ashby and Jones 1994; Huang et al. 2003). The traditional interest (from the 1950s to 1980 s) in density lay in its ease of measurement and correlations with a broad range of timber properties (including hardness and durability). Lindström et al. (2004) examined variation in stiffness (modulus of elasticity, MOE), basic density and MFA in 3-year-old clones of radiata pine. They reported that MOE (derived from acoustic measurement) in young material was much more strongly dependent on MFA than density. Therefore, radiata pine breeders should focus on MFA in preference to density in seeking to improve corewood properties. However, performing MFA measurements on large populations in a breeding programme is impractical, whether considering cost, timescale or logistics. Therefore, an alternative fast, accurate and efficient method is required to determine stiffness within large populations. This can be done with acoustics.

New Zealand radiata pine has been selected for growth and form since the 1950s, basic density since 1975 and disease resistance since 1983 (Dungey et al. 2009). Unfortunately, superior genotypes for growth and form represented in the production populations (seed orchards and clonal production systems) have had very little, if any, screening for stiffness and stability. Acoustics offers a practical way of 'catching up' with stiffness and stability (Huang et al. 2003), through rapid segregation of a subpopulation already demonstrating superior growth performance.

In this study, we hypothesise that one can select very young trees based on acoustic velocity, basic density and shrinkage provided the stems are leant and the opposite wood is examined destructively. Further, we propose to compare the ranking of families selected on acoustic velocity with the ranking based on MFA measured by X-ray diffraction, to validate the idea that selecting for high acoustic velocity implies reducing wood MFA.

\section{Materials and methods}

\subsection{Materials}

A multi-family radiata pine progeny trial was established at Amberley, Canterbury, New Zealand, on a non-irrigated flat land in September 2007. Forty-nine full-sib families displaying improved growth and form were planted in four sections each with 12 blocks with one family member in each. Summer drought in early 2008 and local ponding during the subsequent winter resulted in significant mortality. In August 2008, all trees were staked and leant at an angle of $\sim 30^{\circ}$ to produce $\mathrm{OW}$ on the upper side of the stem and CW on the lower side of the stem, but strong North Western and Southerly winds made it hard to maintain a constant lean. Trees were low pruned and all stem/epicormic needles were rubbed off to create a $300-\mathrm{mm}$ length of clear stemwood immediately above the root collar.

Two sections were tested in September 2009 and April 2010. The surviving trees in the remaining two sections were tested after 34 months in July 2010. Families were ranked according to their acoustic stiffness. This paper focuses on only a subset of 12 families, taken uniformly across the stiffness spectrum in 34 months old trees, which was chosen for extended study 
involving MFA measurements for comparative purposes. The average number of surviving trees per family was 16 (Table 3).

\subsection{Physical and mechanical properties}

A $120-\mathrm{mm}$ long bolt was taken from the base of each tree. This bolt was ripped and trimmed to give two 100-mm long samples (three sides sawn leaving the cambial surface as a slightly curved fourth face). One sample came from the upper side of the lean yielding OW and the other sample from the lower side yielding CW. Full experimental procedures are described in Chauhan et al. (2013) and only a summary is provided here. Length of samples was measured very precisely in the green condition using a specifically designed jig. Green volumes of the irregularly shaped samples were measured by water displacement method. Samples were then dried at $35^{\circ} \mathrm{C}$ until they reached constant mass, which here corresponded to a final moisture content (MC) of approximately $5 \%$. Length and volume measurements were repeated as described previously, and the ratio of green to dried state measurements expressed as percent was used to provide shrinkages. Density $(\rho)$ was calculated from the dry weight ( $5 \% \mathrm{MC})$ and volume of samples. Dynamic modulus of elasticity (hereafter referred to as $\mathrm{MOE}_{\text {dynamic }}$ ) was determined by the product of the resonance acoustic velocity squared $\left(V^{2}\right)$ measured using WoodSpec, developed by Industrial Research Ltd (Lower Hutt, New Zealand) and the previously determined wood density:

$\mathrm{MOE}_{\text {dynamic }}=V^{2} \rho$

\subsection{Microfibril angle}

In order to measure MFA, samples measuring $10 \mathrm{~mm} \times 5 \mathrm{~mm} \times$ $1.5 \mathrm{~mm}$ (longitudinal $\times$ tangential $\times$ radial) were prepared from the previously tested specimens, with the MFA samples being located as close to the bark side as possible. X-ray diffraction was performed at the School of Biological Sciences, University of Auckland. The instrumentation comprised of a Rigaku (Tokyo, Japan) MicroMax-007HF generator outputting $40 \mathrm{kV}$ and $30 \mathrm{~mA}$, a rotating copper anode, an Osmic (Michigan, USA) VariMax-HF mirror and a Mar (Norderstedt, Germany) $345 \mathrm{dtb}$ detector. The beam was orientated in the radial direction of the wood samples with exposure set to $3 \mathrm{~min}$. Samples were positioned at a distance of $200 \mathrm{~mm}$ from the detector. In order to check the homogeneity of results, a second measurement, located $1 \mathrm{~mm}$ in the longitudinal direction from the first measurement, was taken. The open source software 'The Area Diffraction Machine Version 1' (http://code.google.com/p/ areadiffractionmachine/) was used to integrate the intensity of the diffraction profile, at a Bragg angle (2) of 18.4 to $22.1^{\circ}$ representing the 200 planes of cellulose, $360^{\circ}$ about $\chi$. Cave and Robinson's method (Cave and Robinson 1998) was used to interpret the integrated diffraction profiles. The method assumes that the MFA distribution is a simple Gaussian and the outer flanks of the 200 intensity profile arise from the cell walls normal to the beam, i.e., the tangential walls. The angular distance from the equator to the point of inflexion of the intensity curve that cuts the zero intensity axis is given by the value $T$, originally described by Meylan (1967). $T$ values can be equated to a function of mean MFA and the standard deviation $(\sigma)$ of the MFA distributed in the cell wall planes normal to the beam as follows:

$T=\mathrm{MFA}+2 \sigma$

$T$ is considered more useful than the simple mean MFA alone as it additionally describes the distribution of the microfibril angles within the S2 layer (Cave and Robinson 1998).

\subsection{Statistical analysis}

All data was analysed using statistical software R ( R Development Core Team 2011). The significance of the effect of wood type in describing difference in the measured acoustic velocity squared, basic density, $T$, MFA, $\sigma$, longitudinal and volumetric shrinkage was investigated by paired $t$ test. The Pearson correlation was analysed between wood properties independently in OW and CW. The families were ranked using mean values of $\mathrm{OW}$, and the variability attributed to family effect in OW was calculated using the following model:

$y=\mu+R+\mathrm{FC}+\mathrm{TID}+e$

where $\mu$ is the fixed effect of the overall mean. $R$, FC, TID and $e$ represent the random effects of replicate, family, tree identity and residuals, respectively. The expectation of the response variable is $E[y]=\mu$, and random effects have zero means and variances ${\sigma_{R}}^{2}, \sigma_{F C}{ }^{2}, \sigma_{T I D}^{2}$ and $\sigma_{e}^{2}$.

\section{Results}

\subsection{Wood properties}

The mean value along with range of the measured properties for opposite wood and compression wood are given in Table 1. The wood types differ significantly in all the physical and mechanical properties except $T$ values. Opposite wood is characterised by a lower basic density, higher dry acoustic velocity $^{2}$, lower longitudinal shrinkage and greater volumetric shrinkage than observed in compression wood. The average basic density of CW was nearly $52 \%$ higher than OW density; however, the acoustic velocity squared of OW was only $20 \%$ higher than in CW. Consequentially, dynamic MOE of CW was about $15 \%$ higher than in opposite wood due to a higher wood density of CW. In this very young wood, the MFA was lower and $\sigma$ was higher in OW than in $\mathrm{CW}$.

Table 2 shows a matrix of Pearson's correlations revealing the strength of phenotypic association between different 
Table 1 Means and ranges of wood properties in opposite wood $(n=194)$ and compression wood $(n=163)$ from diametrically opposing sides of young Pinus radiata trees

\begin{tabular}{|c|c|c|c|c|c|c|}
\hline \multirow[t]{2}{*}{ Variable } & \multicolumn{3}{|c|}{ Opposite wood } & \multicolumn{3}{|c|}{ Compression wood } \\
\hline & Mean & Min & Max & Mean & Min & $\operatorname{Max}$ \\
\hline Basic density $\left(\mathrm{kg} / \mathrm{m}^{3}\right)$ & 364 & 304 & 437 & 552 & 398 & 687 \\
\hline Dry acoustic velocity $^{2}(\mathrm{~km} / \mathrm{s})^{2}$ & 7.12 & 5.11 & 10.18 & 5.71 & 4.62 & 7.73 \\
\hline Dynamic modulus (GPa) & 2.97 & 1.95 & 4.39 & 3.42 & 2.59 & 4.36 \\
\hline$\sigma\left(^{\circ}\right)$ & 11.5 & 10 & 13 & 8.5 & 7 & 10 \\
\hline $\operatorname{MFA}\left({ }^{\circ}\right)$ & 39 & 28 & 48 & 44 & 36 & 53 \\
\hline$T(\mathrm{MFA}+2 \sigma)\left(^{\circ}\right)$ & 62 & 50 & 71 & 62 & 55 & 69 \\
\hline Longitudinal shrinkage (\%) & 1.03 & 0.15 & 1.8 & 3.44 & 1.82 & 4.98 \\
\hline Volumetric shrinkage (\%) & 12.47 & 7.11 & 20.01 & 8.17 & 5.42 & 15.5 \\
\hline
\end{tabular}

MFA is mean microfibril angle obtained from the Gaussian distribution of the X-ray diffraction profile, $\sigma$ is the standard deviation of that distribution and $T$ is a combination of the two (Cave and Robinson 1998)

properties. Coefficients in the upper diagonal are for OW and in the lower diagonal matrix are for CW. In OW, there was a significant $(p<0.01)$ negative correlation between acoustic velocity $^{2}$ and MFA indicating that these can be considered together. A non-significant $(p=0.28)$ correlation indicates that MFA is a distinct variable to basic density. The correlation between velocity $^{2}$ and density was significant $(p<0.01)$ but weak $(r=$ $0.24)$. Density and velocity ${ }^{2}$ were positively correlated to dynamic modulus, although it is necessary to remember that $\mathrm{MOE}_{\text {dynamic }}$ is a composite variable that is the product of these two variables. Density, velocity ${ }^{2}$ and MFA are significantly correlated to longitudinal shrinkage, but the strength of the correlation was weak $(r=-0.34)$ for basic density. There was only negligible difference in the strength of correlation between longitudinal shrinkage and either MFA or $T$. The same was true for $\mathrm{MOE}_{\text {dynamic. Acoustic velocity }}{ }^{2}$, MFA and density are significantly $(p<0.01)$ but weakly correlated to volumetric shrinkage. The strength of the phenotypic relationship between velocity $^{2}$ and MFA is shown in Fig. 1, which also provides an ordinary least squares regression equation to convert velocity ${ }^{2}$ to MFA in OW and CW. Compression wood showed a more complex story for the correlations. Basic density was positively correlated to longitudinal shrinkage, volumetric shrinkage and MFA, but it was negatively correlated to acoustic velocity ${ }^{2}$.

\subsection{Ranking of families}

The properties of OW and CW behaved independently; there was no correlation between the MFA of OW and MFA of CW (Fig. 2), and this was true for other properties too (not shown). This is consistent with other findings in radiata pine where wood properties in compression wood and opposite are independently controlled by the tree (Chauhan et al. 2013). Ultimately, in tree breeding, the main interest is to select the best 'normal' wood properties; thus, ranking is discussed only for OW.

Phenotypic means of measured properties in OW together with the coefficient of variation (CV) for the 12 families are given in Table 3. Figure 3 displays the correlation between the family means for acoustic velocity squared and MFA. There is a strong negative association between the family means for acoustic velocity ${ }^{2}$ and MFA,

Table 2 Pearson Correlation matrix (with $p$ values in parentheses) for wood properties of young Pinus radiata

\begin{tabular}{|c|c|c|c|c|c|c|c|}
\hline Variable & $\begin{array}{l}\text { Basic density } \\
\left(\mathrm{kg} / \mathrm{m}^{3}\right)\end{array}$ & $\begin{array}{l}\text { Acoustic velocity }^{2} \\
(\mathrm{~km} / \mathrm{s})^{2}\end{array}$ & $\begin{array}{l}\text { Dynamic } \\
\text { modulus (GPa) }\end{array}$ & $T\left(^{\circ}\right)$ & $\operatorname{MFA}\left({ }^{\circ}\right)$ & $\begin{array}{l}\text { Longitudinal } \\
\text { shrinkage }(\%)\end{array}$ & $\begin{array}{l}\text { Volumetric } \\
\text { shrinkage (\%) }\end{array}$ \\
\hline Basic density $\left(\mathrm{kg} / \mathrm{m}^{3}\right)$ & & $0.24(<0.01)$ & $0.66(<0.01)$ & $-0.22(0.09)$ & $-0.08(0.28)$ & $-0.34(<0.01)$ & $-0.23(<0.01)$ \\
\hline Acoustic velocity $^{2}(\mathrm{~km} / \mathrm{s})^{2}$ & $-0.45(<0.01)$ & & $0.88(<0.01)$ & $-0.75(<0.01)$ & $-0.73(<0.01)$ & $-0.80(<0.01)$ & $-0.33(<0.01)$ \\
\hline Dynamic modulus (GPa) & $0.73(<0.01)$ & $0.27(<0.01)$ & & $-0.66(<0.01)$ & $-0.58(<0.01)$ & $-0.75(<0.01)$ & $-0.22(<0.01)$ \\
\hline $\mathrm{T}(\mathrm{MFA}+2 \sigma)\left({ }^{\circ}\right)$ & $0.18(0.02)$ & $-0.55(<0.01)$ & $-0.22(<0.01)$ & & $0.82(<0.01)$ & $0.62(<0.01)$ & $0.27(<0.01)$ \\
\hline $\operatorname{MFA}\left({ }^{\circ}\right)$ & $0.23(<0.01)$ & $-0.53(<0.01)$ & $-0.15(0.06)$ & $0.79(<0.01)$ & & $0.67(<0.01)$ & $0.28(<0.01)$ \\
\hline Longitudinal shrinkage (\%) & $0.66(<0.01)$ & $-0.71(<0.01)$ & $0.18(0.02)$ & $0.45(<0.01)$ & $0.51(<0.01)$ & & $0.40(<0.01)$ \\
\hline Volumetric shrinkage (\%) & $0.33(<0.01)$ & $-0.37(<0.01)$ & $0.17(0.03)$ & $0.27(<0.01)$ & $0.28(<0.01)$ & $0.38(<0.01)$ & \\
\hline
\end{tabular}

Above diagonal for opposite wood $(n=194)$ and below diagonal for compression wood $(n=163)$ 
Fig. 1 Relationship between microfibril angle (MFA) and acoustic velocity ${ }^{2}\left(V^{2}\right)$ in opposite wood (OW) and compression wood (CW). Triangles represent $\mathrm{OW}$, with a regression equation, MFA $=62-3.22\left(V^{2}\right)$ with a $r^{2}$ of 0.54. Circles represent $\mathrm{CW}$, with a regression equation, $\mathrm{MFA}=63$ $3.23\left(V^{2}\right)$ with a $r^{2}$ of 0.28

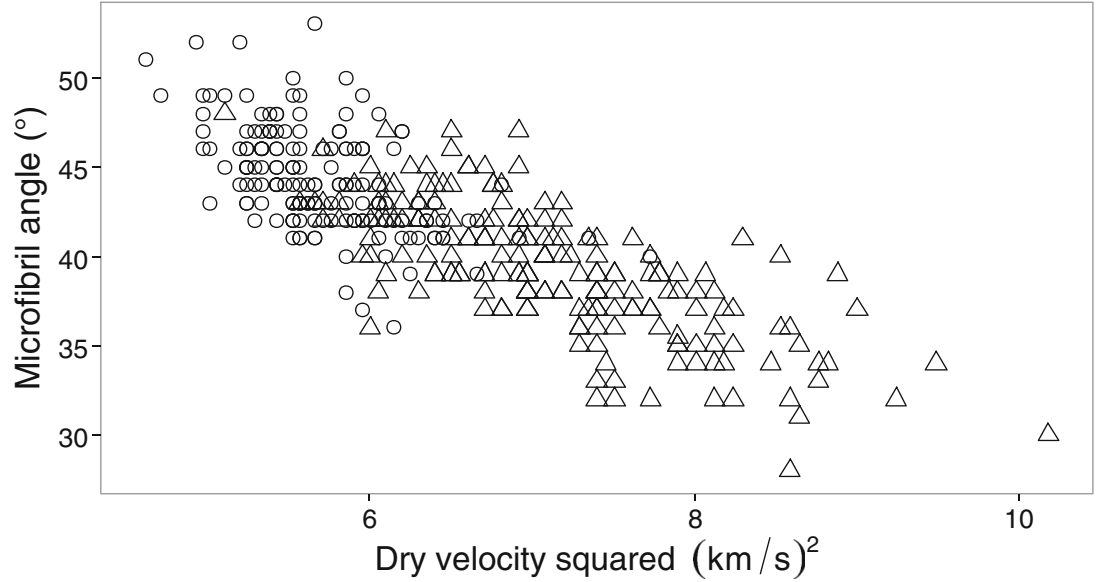

with a Spearman correlation (as we are interested in ranking families) of 0.81 . There is a large within-family variation in MFA and acoustic velocity ${ }^{2}$ in OW; Fig. 3 represents the within-family variation in MFA and acoustic velocity ${ }^{2}$ in best family $\mathrm{A}$ and worst family $\mathrm{L}$ ranked on the basis of stiffness and longitudinal shrinkage of OW.

\section{Discussion}

\subsection{Wood properties}

The basic density of CW was comparable to that reported in the literature (Donaldson et al. 2004) for leaning 18 years old P. radiata trees $\left(572 \mathrm{~kg} / \mathrm{m}^{3}\right)$, but the OW basic density was lower than that reported for OW $\left(477 \mathrm{~kg} / \mathrm{m}^{3}\right)$ in the same study. The low density of OW in the present study is attributed to the juvenile nature of samples, as radiata pine density is known to increase with cambial age (Cown et al. 2002). On material of a comparable age (Chauhan et al. 2013), the density reported here is of the same magnitude. Longitudinal shrinkage in $\mathrm{OW}$ and $\mathrm{CW}$ were comparable to previously reported results (Brennan et al. 2012; Chauhan et al. 2013).
The MFA range in OW was $28-48^{\circ}$, which is consistent with the results reported by Donaldson (1993) for radiata pine; the range for $\mathrm{CW}$ was from $36^{\circ}$ to $53^{\circ}$. In summary, differences between $\mathrm{OW}$ and $\mathrm{CW}$ were as would be expected and $\mathrm{CW}$ can be seen to have a detrimental impact on structural timber properties. These differences between properties of OW and $\mathrm{CW}$ emphasise the difficulties that could arise when attempting to determine the 'true' wood properties of normal wood in a vertical stem where non-experimentally controllable intermixing of wood types occurs within the cross-section. Further, the lack of phenotypic correlation between $\mathrm{OW}$ and $\mathrm{CW}$ properties was in agreement with an earlier study (Chauhan et al. 2013) and suggests that wood properties of OW and CW are independently controlled by a tree; therefore, a tree exhibiting desirable OW properties will not necessarily exhibit desirable $\mathrm{CW}$ properties. This has implications for selection and tilting the trees successfully allowed us to isolate the $\mathrm{CW}$ phenotype from analysis relating to selection.

When considering phenotypic correlations, our main aim was to determine if there was a strong link between MFA and velocity $^{2}$ and we found this to be the case. The strength of that relationship did not change notably whether we considered $T$,
Fig. 2 Relationship between microfibril angle in compression wood $(\mathrm{CW})$ and microfibril angle in opposite wood (OW) in young radiata pine $(n=163)$. Circles represent individual trees

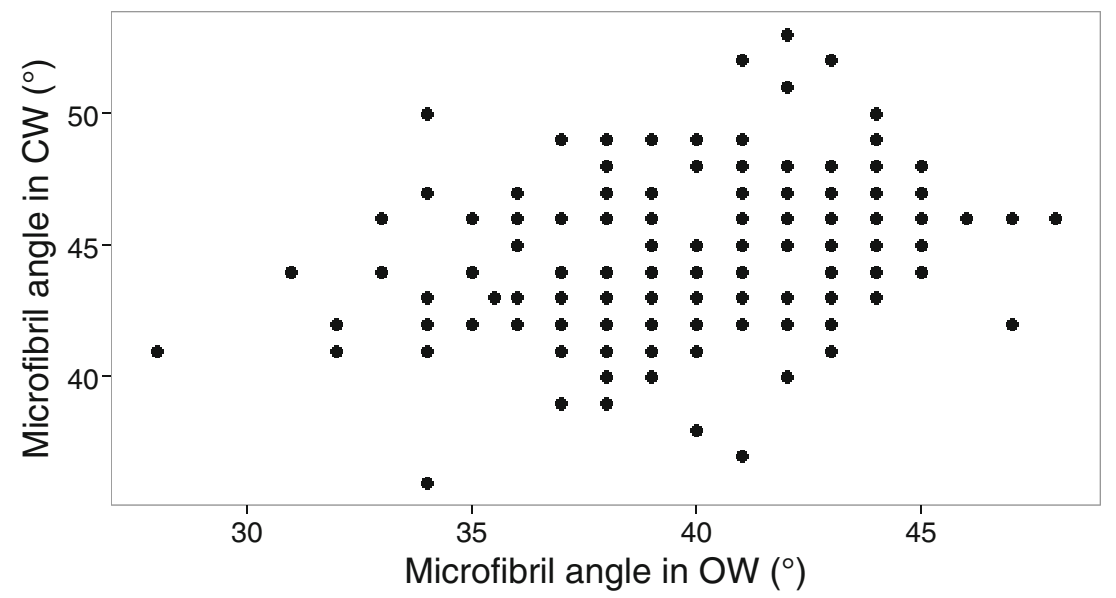


Table 3 Mean values of wood properties and coefficients of variation in opposite wood for 12 radiata pine families

\begin{tabular}{|c|c|c|c|c|c|c|c|c|c|c|c|c|c|}
\hline \multirow[b]{2}{*}{ Family code } & \multirow[b]{2}{*}{ No. of samples } & \multicolumn{2}{|c|}{$\begin{array}{l}\text { Basic density } \\
\left(\mathrm{kg} / \mathrm{m}^{3}\right)\end{array}$} & \multicolumn{2}{|c|}{$\begin{array}{l}\text { Acoustic velocity }{ }^{2} \\
(\mathrm{~km} / \mathrm{s})^{2}\end{array}$} & \multicolumn{2}{|c|}{$\begin{array}{l}\text { Dynamic modulus } \\
(\mathrm{GPa})\end{array}$} & \multicolumn{2}{|c|}{$\begin{array}{l}\text { Longitudinal } \\
\text { shrinkage (\%) }\end{array}$} & \multicolumn{2}{|c|}{$\begin{array}{l}\text { Volumetric } \\
\text { shrinkage (\%) }\end{array}$} & \multicolumn{2}{|c|}{ MFA $\left({ }^{\circ}\right)$} \\
\hline & & Mean & CV (\%) & Mean & CV $(\%)$ & Mean & CV (\%) & Mean & CV $(\%)$ & Mean & CV (\%) & Mean & CV $(\%)$ \\
\hline A & 20 & 371 & 5.6 & 7.89 & 9.6 & 3.28 & 12.2 & 0.68 & 26.5 & 10.53 & 11.0 & 37.3 & 8.8 \\
\hline $\mathrm{B}$ & 16 & 384 & 6.9 & 7.64 & 8.5 & 3.34 & 12.9 & 0.78 & 34.7 & 11.94 & 11.7 & 38.8 & 8.9 \\
\hline $\mathrm{C}$ & 16 & 377 & 8.6 & 7.65 & 8.4 & 3.29 & 15.5 & 0.82 & 28.0 & 11.95 & 10.6 & 36.8 & 9.9 \\
\hline $\mathrm{D}$ & 20 & 361 & 6.8 & 7.72 & 10.6 & 3.21 & 12.1 & 0.96 & 28.1 & 13.13 & 22.1 & 36.8 & 9.7 \\
\hline $\mathrm{E}$ & 9 & 370 & 7.1 & 7.04 & 4.3 & 2.97 & 8.8 & 0.87 & 27.5 & 12.23 & 16.7 & 39.1 & 5.0 \\
\hline $\mathrm{F}$ & 17 & 359 & 5.1 & 7.23 & 9.4 & 2.94 & 10.2 & 0.84 & 27.6 & 11.48 & 15.5 & 38.7 & 11.6 \\
\hline G & 18 & 347 & 7.0 & 7.11 & 11.7 & 2.85 & 14.7 & 1.02 & 24.3 & 13.19 & 16.9 & 38.1 & 6.9 \\
\hline $\mathrm{H}$ & 15 & 347 & 6.9 & 6.37 & 8.3 & 2.54 & 9.8 & 1.28 & 21.3 & 12.80 & 10.6 & 40.5 & 6.0 \\
\hline I & 11 & 344 & 7.2 & 6.59 & 7.6 & 2.58 & 7.3 & 1.17 & 23.1 & 12.23 & 13.4 & 40.6 & 9.4 \\
\hline $\mathrm{J}$ & 16 & 371 & 5.7 & 6.41 & 9.4 & 2.74 & 7.1 & 1.26 & 25.9 & 13.28 & 18.7 & 41.1 & 8.1 \\
\hline $\mathrm{K}$ & 19 & 377 & 8.1 & 6.68 & 12.3 & 2.93 & 17.2 & 1.29 & 31.0 & 13.98 & 12.0 & 42.5 & 6.3 \\
\hline $\mathrm{L}$ & 16 & 361 & 5.3 & 6.62 & 4.8 & 2.74 & 7.7 & 1.39 & 19.4 & 12.76 & 17.8 & 41.7 & 5.3 \\
\hline
\end{tabular}

which combines the mean MFA determined from X-ray diffraction profile with the standard deviation, or the mean MFA as a discrete variable. The same was true when we considered the phenotypic correlation of mean MFA or $T$ with other variables. Given the limited range of MFA and velocity ${ }^{2}$ in this study, due to the young age of the material, we believe the strength of correlation achieved is good. It is likely that broadening the range of MFA by including pith to bark measurements would increase the strength of the correlation. A further consideration for the results presented is that the MFA was measured on a volumetric subsample of the piece measured for velocity; had it been practical to measure the entire sample, the correlation might have been higher. This might explain why longitudinal shrinkage was slightly better correlated to velocity $^{2}$ than MFA, as velocity ${ }^{2}$ is a bulk measurement. The fact that velocity ${ }^{2}$ is a bulk measurement adds a further benefit to this measurement technique, in addition to the obvious efficiency and subsequent cost effectiveness benefits over Xray diffraction. None of the measured variables showed a strong correlation with volumetric shrinkage. Others have suggested that this relationship is likely affected by the hemicellulose chemistry and structure (Floyd 2005; Newman 2005).

\subsection{Ranking of families}

Through examination of the literature, we had already established that in order to improve the corewood properties of longitudinal shrinkage and stiffness, we would like to select trees with low MFA. A central question for very early screening is 'Are we improving the underlying desirable but hard to assess traits (MFA, stiffness, stability) when using acoustic velocity $^{2}$ as a surrogate selection criterion?' Table 2 showed high significant correlations between acoustic velocity ${ }^{2}$ and MFA, stiffness and longitudinal shrinkage. In addition, Fig. 3 showed a strong relationship at the family means level between acoustic velocity ${ }^{2}$ and MFA, with a strong negative
Fig. 3 Relationship between mean microfibril angle (MFA) and mean dry acoustic velocity ${ }^{2}$ of 12 families in opposite wood in young radiata pine. The Spearman ranking correlation between mean values was 0.81 . Circles with letters represent individual families

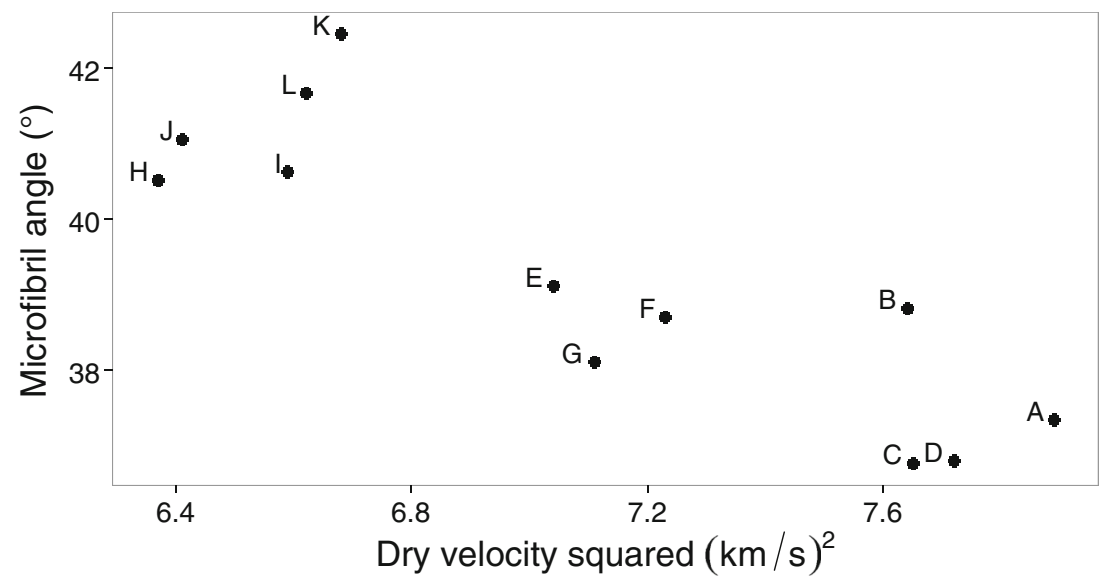


Fig. 4 Variation in microfibril angle and dry velocity ${ }^{2}$ in opposite wood within the best (circles) and the worst (triangles) family of young radiata pine. The best $(A)$ and the worst $(L)$ families were selected on the basis of stiffness and longitudinal shrinkage (Table 3)

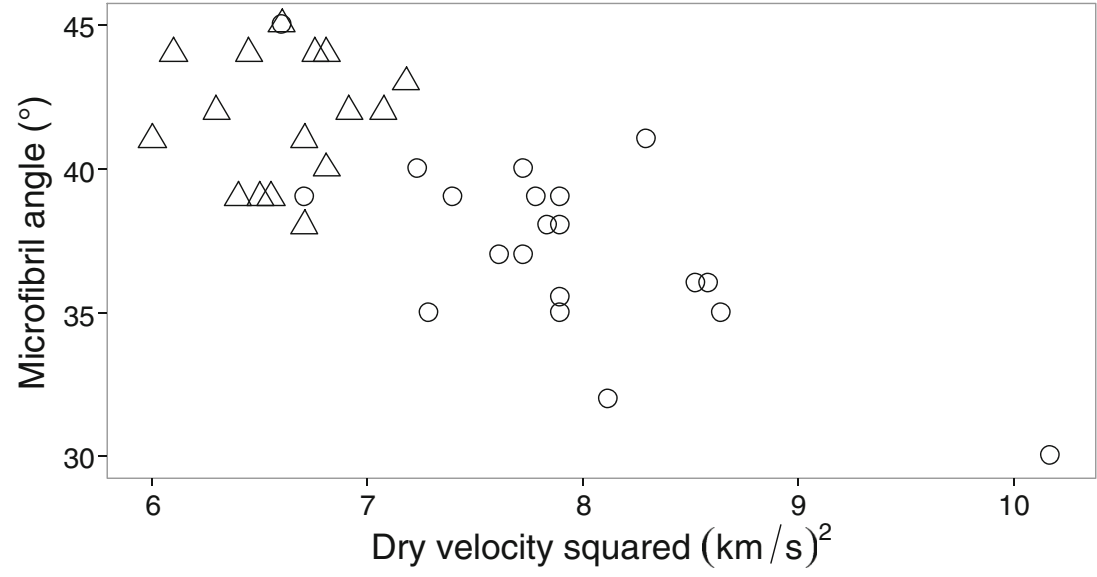

Spearman's correlation supporting the strategy of selecting for high acoustic velocity ${ }^{2}$ to reduce MFA.

Between-family variability of wood properties was lower than the within-family variation, supporting the use of selection indices that exploit both between- and within-family variability. The variation in MFA attributed to family effect in OW was $22 \%$. There were issues with the trial site, as in the first growing season there was localised water logging, which resulted in growth variability and death of some trees. Thus, microsite variability unaccounted for by the experimental design likely explained part of the high within-family variation. Hence, Fig. 4 shows a large within-family variation in acoustic velocity ${ }^{2}$ and MFA in the best and worst families, selected on the basis of stiffness and longitudinal shrinkage. Even so, there is clear demarcation between the best four families (A, $\mathrm{B}, \mathrm{C}$ and $\mathrm{D}$ with high acoustic velocities and dynamic moduli) and worst families ( H, I, J and L), which is very evident in Fig. 3.

\section{Conclusion}

This analysis confirms that, for radiata pine, the underlying desirable characteristic influencing stiffness and stability in young trees is low MFA in OW. However, acoustic velocity ${ }^{2}$ delivers comparable assessments of stiffness and stability, and these values can be determined more readily.

This scoping study compared wood properties of radiata pine families that have been improved for growth and form and are currently operationally deployed in forest plantings. By identifying families with superior wood properties, breeders have the opportunity to rebalance production populations, augmenting the gain already achieved for growth and form. We found that acoustic velocity ${ }^{2}$ performs very well at ranking the families for intrinsic wood properties, fully comparable to X-ray diffraction (MFA). In practice, it is possible to cut, prepare and screen for physical and mechanical properties using acoustics and basic density very quickly and more cheaply compared to X-ray diffraction. Having validated this proposition in this study, subsequent selection procedures can omit reference to MFA so saving money and time.

The key driver for this work is the proposition that it is the poorest wood, adjacent to the pith, that destroys value, and such wood can be identified early ( $<3$ years.). Delaying selection to focus on improving outerwood provides quickly diminishing returns, as the price premium for higher quality is much smaller. A further advantage of early selection is that generation interval for breeding is much shorter, achieving higher response to selection per year.

Acknowledgments We would like to thank Professor John Walker, University of Canterbury, for his valuable advice and comments. This work was supported by the New Zealand Foundation for Research, Science and Technology with participation by Forestry Corporation of New South Wales, Forest \& Wood Products Australia, Future Forests Research (with Scion), Proseed Ltd, Radiata Pine Breeding Co., the Solid Wood Initiative and Weyerhaeuser (USA). Proseed Ltd provided the seedlings and the land for the trial.

Open Access This article is distributed under the terms of the Creative Commons Attribution 4.0 International License (http:// creativecommons.org/licenses/by/4.0/), which permits unrestricted use, distribution, and reproduction in any medium, provided you give appropriate credit to the original author(s) and the source, provide a link to the Creative Commons license, and indicate if changes were made.

\section{References}

Apiolaza L (2009) Very early selection for solid wood quality: screening for early winners. Ann For Sci 66:601-611

Apiolaza L, Chauhan S, Hayes M, Nakada R, Sharma M, Walker J (2013) Selection and breeding for wood quality a new approach. N Z J For $58: 33$

AS/NZS 1748. Timber-Stress-graded-Product requirements for mechanically stress-graded timber. Joint publication of Standards Australia, Homebush, NSW and Standards New Zealand, Wellington, New Zealand

Ashby M, Jones D (1994) Engineering materials 2: an introduction to microstructures, processing and design, 1986. Pergamon Press, Oxford 
Brennan M, McLean JP, Altaner CM, Ralph J, Harris PJ (2012) Cellulose microfibril angles and cell-wall polymers in different wood types of Pinus radiata. Cellulose 19:1385-1404

Burdon R (1975) Compression wood in Pinus radiata clones on four different sites. N Z J For Sci 5:152-164

Burdon RD, Kibblewhite RP, Walker JCF, Megraw RA, Evans R, Cown DJ (2004) Juvenile versus mature wood: a new concept, orthogonal to corewood versus outerwood, with special reference to Pinus radiata and Pinus taeda. For Sci 50:399-415

Cave ID (1969) The longitudinal young's modulus of Pinus radiata. Wood Sci Technol 3:40-48

Cave ID, Robinson W (1998) Interpretation of (002) diffraction arcs by means of a minimalist model. Paper presented at the Proceedings of the International Union of Forest Research Organizations/ International Association of Wood Anatomists International Workshop on the Significance of Microfibril Angle to Wood Quality, New Zealand

Chauhan SS, Sharma M, Thomas J, Apiolaza LA, Collings DA, Walker JC (2013) Methods for the very early selection of Pinus radiata D. Don. for solid wood products. Ann For Sci 70:439-449

Cown D, McConchie D, Young G (1991) Radiata pine: wood properties survey. FRI Bull For Res Inst N Z 53:45-58

Cown DJ, McKinley RB, Ball RD (2002) Wood density variation in 10 mature Pinus radiata clones. N Z J For Sci 32:48-69

Donaldson LA (1993) Variation in microfibril angle among three genetic groups of Pinus radiata trees. N Z J For Sci 23:90-100

Donaldson LA, Grace J, Downes GM (2004) Within-tree variation in anatomical properties of compression wood in radiata pine. IAWA J 25:253-272

Drew A, Downes G (2010) Predicting wood quality to improve sawlog value in radiate pine. Forest $\&$ Wood Products Australia, Melbourne
Dungey HS, Matheson AC, Kain D, Evans R (2006) Genetics of wood stiffness and its component traits in Pinus radiata. Can J For Res 36: $1165-1178$

Dungey HS, Brawner JT, Burger F, Carson M, Henson M, Jefferson P, Matheson A (2009) A new breeding strategy for Pinus radiata in New Zealand and New South Wales. Silvae Genet 58:28-38

Floyd S (2005) Effect of hemicellulose on longitudinal shrinkage in wood. Paper presented at the hemicelluloses workshop, New Zealand

Huang CL, Lindström H, Nakada R, Ralston J (2003) Cell wall structure and wood properties determined by acoustics - a selective review. Holz Roh Werkst 61:321-335

Lindström H, Harris P, Sorensson CT, Evans R (2004) Stiffness and wood variation of 3-year old Pinus radiata clones. Wood Sci Technol 38: 579-597

Meylan B (1967) Measurement of microfibril angle by X-ray diffraction. For Prod J 17:51-58

Meylan B (1968) Cause of high longitudinal shrinkage in wood. For Prod J $18: 75-78$

Newman R (2005) Solid-state NMR as a tool for studying dancing molecules. Paper presented at the hemicelluloses workshop New Zealand

Timell T (1986) Compression wood in gymnosperms 1, vol 1. Springer, Berlin

Walker JCF, Butterfield BG (1996) The importance of microfibril angle for the processing industries. N Z J For 40:34 40

Xu P, Walker J (2004) Stiffness gradients in radiata pine trees. Wood Sci Technol 38:1-9 